\title{
Cairu e a patologia \\ da Revolução
}

PEDRO MEIRA MONTEIRO

A R evolução é sempre uma religião que erra de objetivo.

(Alceu Amoroso Lima, Thor ePan, 1940)

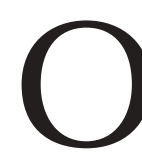

VISCONDE de Cairu é um autor bastante conhecido no campo das Ciências Sociais e entre historiadores, notadamente por conta de seus escritos de cunho econômico e por sua atuação política, não apenas como deputado constituinte em 1823, mas como um dos idealizadores da abertura dos portos em 1808, ou ainda como um dos principais censores da corte. Como muitos de seus contemporâneos, formou-se numa C oimbra supostamente varrida dos resquícios da velha Escolástica, conectado portanto a muitas das mais modernas discussões filosóficas, morais e econômicas - num tempo em que a moral e a economia apenas começavam a distinguir-se. U m homem seguramente bem informado, sobretudo se se tiver em conta o quão provinciana era a corte do Rio de Janeiro.

Como dado anedótico, note-se que Cairu é um censor muito consciencioso, e não se pode dizer que estulto, como são alguns censores, justamente porque sabia detectar com precisão o poder daquilo que lia. Tanto assim que, muitas das obras censuradas e portanto vedadas à leitura dos seus compatriotas aparecerão em sua obra magna moralizante, que é a Constitui ção moral e deveres do cidadão, editada entre 1824 e 1825 na I mprensa R égia do R io de J aneiro. I nteressante que essas fontes proibidas passem por uma espécie de filtro moralizante, capaz de ressignificá-las, dando-Ihes um enquadramento muito particular, através do qual são "explicadas" para o leitor, no mais das vezes purgadas de seus efeitos maléficos. $\mathrm{N}$ otável o caso das máximas de La R ochefoucauld, utilizadas como 0 veneno terrível que ofereceria, a bem dizer, uma ética especular, isto é, o exato contrário daquilo que os jovens leitores da obra deveriam seguir, na linha das boas e transparentes ações. Aquilo que La Rochefoucauld desvendava - o império do amor-próprio - era o alvo com o qual se batia o visconde brasileiro.

D esde que é tão candente o tema das paixões e do nacionalismo, parece razoável, e mesmo importante, discutir o discurso do visconde de Cairu, procurando fixar não o caráter apaixonado de seu nacionalismo, mas sim o temor que Ihe causavam as mesmas paixões. $E$ aqui, parece-me, o registro deve nos remeter às paixões no seu sentido mais antigo e original, isto é, não o desejo que brota do sujeito, senão este movimento da alma que independe de nossa vontade. Conviria, daí, retornar a um tempo anterior ao século das luzes. 
Refiro-me às paixões que tomam de assalto os homens, como aquela ira fundante homérica, ou, num módulo mais próximo e compreensível, as paixões do desenhista e pintor Charles le Brun, no século XVII francês (Figura 1).

Se reparamos bem, há ali, na figuração das paixões, uma dramaticidade que reclama o rosto, ou antes, que apenas se deixa compreender nas feições contorcidas, na face subjugada pela força - concreta - de uma paixão. É um arrebatamento, rapto, ou intrusão de uma outra criatura, que toma o humano, para desfigurá-lo. O s desenhos foram publicados em 1727 na França, por Audran, que se refere a L e B run lembrando que o mestre justamente seguira os antigos filósofos em sua consideração das paixões como um movimento da alma em sua parte sensitiva: "ele diz que o que causa à Alma alguma paixão, faz fazer ao corpo certos movimentos, e produz alterações das quais ele reporta as principais" ${ }^{1}$.

Cortesia do Autor
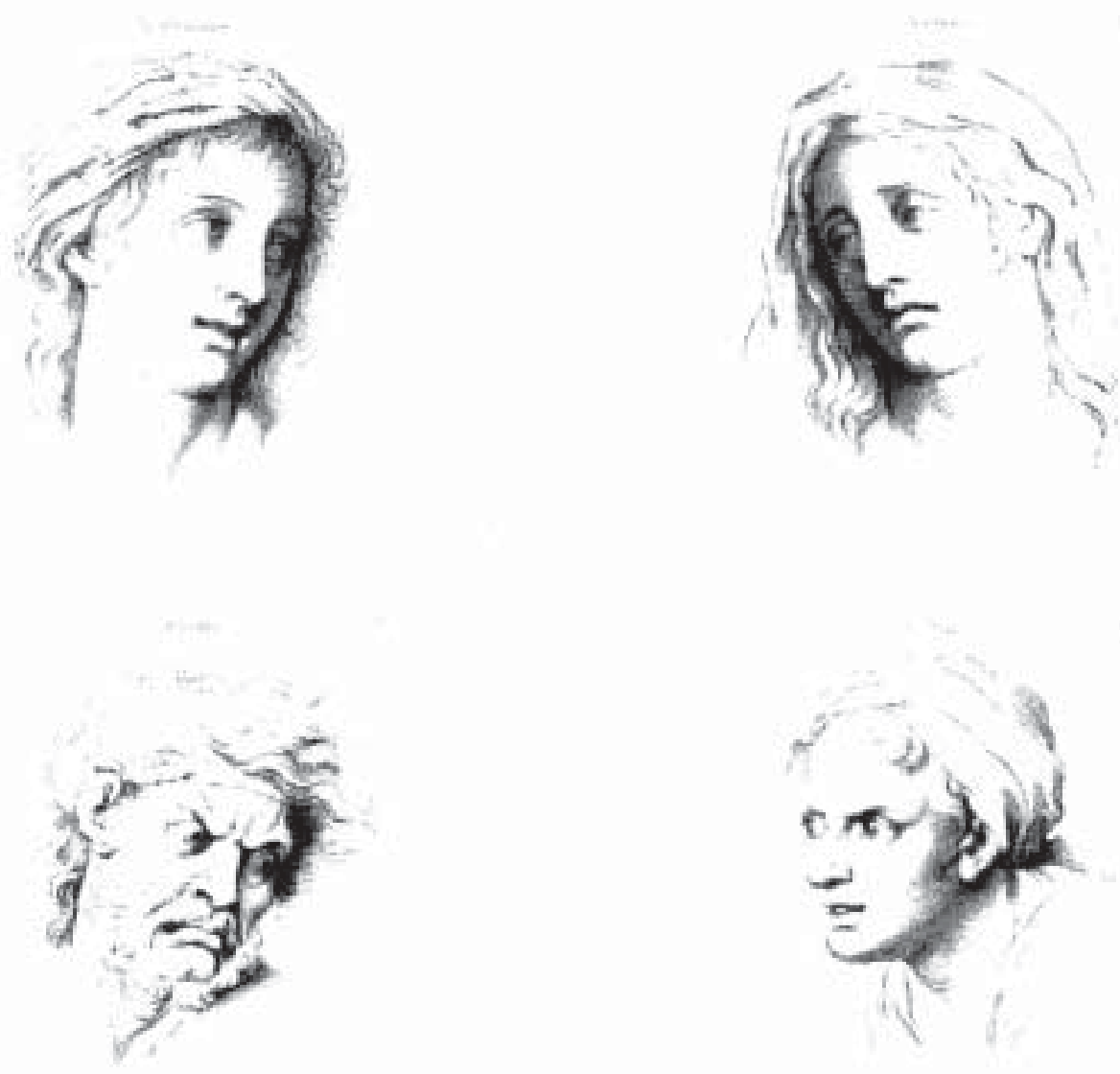

Figura 1 - Charles le Brun. Expressi ons des passi ons de l'A me. (Admiração, Tristeza, Cólera, D esejo.) [C larles le Brun. Expressi onsdespassionsdel'A me(1727). Publication BnF del'édition de Paris, Aux amateurs de livres, 1990, Gallica (gallica.bnf.fr).] 
Parece que $C$ airu anda a meio caminho dessas concepções das paixões, mas creio que, no seu caso, ainda devamos operar com as paixões no seu sentido antigo, como algo que afeta, que se impõe aos homens, que os cega, pondo-os fora de si e de sua natureza, que os torna, portanto, loucos rematados.

D esde que se refere a um desvio da natureza, não será à toa se a referência de Cairu seja, precisamente, aristotélica. No segundo volume da Constituição moral edeveres do cidadão, o escritor se dirige aos seus jovens leitores lembrando que a "Consciência" deveria fazer-se "Voz da N atureza", executando a "O rdem M oral", que seria o guia infalível da ação.

Surge aí uma interessante passagem em que o nosso autor lembra que os monstros physicos não são os padrões da creação, nem se devem allegar por modelos da natureza. Bem disse A ristóteles $=0$ que he natural, deve-se considerar nas cousas que operão conforme o seu perfeito estado, e não nas que se achão corruptas $=$. O s salvagens são os monstros da Especie humana, que até deformão a sua physiognomia².

O desvio aqui significa a inobservância da natureza, contrariando a maior lição da ética aristotélica. L ogo, a partir dessa passagem, C airu se embrenha numa discussão de ordem teológica sobre o primeiro e mais trágico desvio dos homens, para sugerir, talvez em bom estilo da Segunda E scolástica, que os instintos e sentimentos da $\mathrm{H}$ umanidade não se extinguiram completamente nos povos selvagens, donde se depreende a possibilidade de uma espécie de redenção do selvagem pela mensagem civilizadora, ainda que esse selvagem não seja a página em branco que fora, por exemplo, para um dos primeiros jesuítas, o padre $M$ anuel da Nóbrega.

C reio que a redenção do selvagem pela mensagem civilizadora seja o termo, e talvez a espinha dorsal, da pregação de Cairu. Interessante frisar, nesse particular, o aspecto claramente mi ssionário de sua obra - detal he precisamente notado, recentemente, num texto fundamental de Fernando N ovais e J oséJ obson ${ }^{3},-$ aspecto tão mais curioso quanto nos lembremos que $\mathrm{C}$ airu, como bom egresso dos bancos de uma Coimbra já reformada, pós-pombalina, era um antijesuíta convicto.

$M$ as o que interessa fixar, na linha desta argumentação, é a idéia de uma selvageria como desvio da natureza; desvio que apavora todo amante da 0 rdem, como é o caso de Cairu - mas não só dele, certamente. $\mathrm{Na}$ Constituição moral e deveresdo ci dadão, o perigo do desvio é freqüentemente associado à catástrofe de São D omingos, e creio que ai se possa flagrar, muito claramente, aquilo que os historiadores nomeariam mais tarde como o "haitianismo" das elites, isto é, o temor de que a barbárie dos seguidores de Toussaint L ouverture se repetisse ao sul do Equador.

Vale a pena a leitura de uma passagem muito interessante da C on stitui ção moral, que, logo em seguida, cito parcialmente, e de que excluo, todavia, alguns momentos onde parece revelar-se um bom caminho de pesquisa: refiro-me à 
maneira como Cairu reporta brevemente a saga transatlântica dos africanos; forma que poderia porventura anunciar alguns tópicos bastante conhecidos da poesia romântica brasileira, já que as embarcações negreiras são ali figuradas como "Tumbas ondeantes", e os escravos cativos são descritos por meio de uma fantasmagoria, como seres que definham e fenecem, como " mirrados esquelêtos, e sepulchros ambulantes".

Interrompido o excurso, é interessante notar que o verdadeiro temor de Cairu - um crítico da escravidão, ou ao menos do tráfico - era a possibilidade de queno Brasil se estabelecesse uma "Ethiopia”, ou, nas suas palavras, uma "N igricia”.

A questão é justamente o desvio da natureza que se dá nesse estabelecimento de uma Etiópia no Brasil, com a intrusão do elemento negro. A pergunta de Cairu, defendendo o fim do tráfico, é curiosa:

E como não virão os Europeos nisso a mais enorme violação da O rdem Cosmológica, tendo o Regedor do universo separado os Continentes Africano e Americano por quasi ou mais de mil legoas? Como no horizonte político não divisarão o perigo da extinç̧ão da progenie puritana, necessário effeito de progressiva accumulação de carvões ardentes, quaes depois se afoguearão na Rainha das Antilhas?4

Logo em seguida a essa passagem, Cairu propõe que nos espalhássemos nos Estados U nidos da América, extinguindo o tráfico que lhes introduzira o "C ancro do Barbarismo". I mporta fixar al go aqui. Em primeiro lugar, a riqueza dessas imagens - não obstante seu caráter ominoso, do ponto de vista humano e o fato de que $C$ airu parece revelar-se como escritor exatamente nos momentos em que sua pena se deixa arrebatar por uma potência normativa que, quase instantaneamente, converte-se em potência punitiva. Por estranho que pareça, pretendo sugerir que quanto mais autoritário e preconceituoso, melhor escritor é 0 visconde de Cairu. Talvez porque ele se deixe tomar pela paixão da escrita que, no seu caso, é a paixão política pela hierarquia rígida do espírito e das funções.

0 segundo ponto a se fixar é o imaginário orgânico que parece brotar desse "cancro do barbarismo", ou seja, a doença causada pelo elemento não civilizado que pode repentinamente tomar o poder do corpo, corrompendo o tecido social. M omento em que as paixões - as velhas páthoi gregas - transformam-se modernamente nas diversas patologiasdo organismo. É evidenteque entre L e Brun, D ella Porta e L ombroso, haverá um longo e tortuoso caminho, mas é fato que a figuração do revolucionário, na imaginação criminológica, pode aproximar-se incrivelmente da fis ognomonia que marca os sinais do desvio na própria face humana.

Estamos no século XIX, e é importante lembrar que Cairu, embora talvez nunca tenha lido Comte, tomava de empréstimo ao discurso científico a tópica da "física social", justamente para apontar a correta ordenação do corpo coletivo, isto é, a definição da correta natureza da sociedade, com o controle do desvio no seu justo termo e limite. Ei-nos diante do nascimento da moderna Sociologia, como discurso da O rdem. Tempo de busca e encontro dos corretivos da patologia. 
O utra pequena passagem pode revelar a conexão que nos falta, entre esse desvio horroroso da ordem natural - a Revolução do H aiti - e a R evolução Francesa, a qual, como bom leitor e aliás tradutor de Burke, Cairu considerava a maior e mais calamitosa catástrofe moderna.

A bem dizer, examinando transversalmente a argumentação de Cairu, não é difícil perceber que suas razões filantrópicas, com a defesa do fim do tráfico de escravos, dizem respeito muito mais ao temor causado pela presença negra que à causa da H umanidade, simplesmente. Interessante que, diante desse temor, cabia recriar, no plano textual mesmo, o mal formidável e monstruoso da dupla revolução:

A catastrophe da Raynha das Antilhas, e, por assim dizer, a M etamorphose das I lhas de Sotavento em Nova Nigricia, contra o Systema Cosmológico, e Demarcação dos habitantes da Terra, conforme declara o A postolo das Gentes nos Actos dos Apostolos, são M ales, que vão além de todo o calculo, e que resultarão da fúria dos Enthusiastas da R evolução da França, os quaes ordenarão, em momento de vertigem, na Assembléia $N$ acional o $D$ ecreto da immediata liberdade dos escravos, bradando os A rchitectos de R uínas = Pereção as Colônias, antes que pereção os nossos Princípios $=5$.

É uma passagem riquíssima. Não me alongo nos detalhes, mas vale ressaltar nela uma compreensão um pouco enviesada da mensagem paulina, o que é algo bastante freqüente nessa obra de $C$ airu. $O$ visconde percebe que as $E$ pístolas de Paulo deveriam ser o seu principal intertexto, porque elas são, afinal, uma das mais impressionantes men sagens dirigidas à cidade perdida, à Babilônia-prostituta, figuração bíblica que, sem grande esforço, poderíamos imaginar associada à Paris revolucionária de 1789. U ma mensagem civilizadora, contra a decadência citadina, portanto. Contudo, o aspecto universalizante da pregação paulina é completamente perdido quando Cairu se refere a essa patriótica demarcação dos limites das gentes: africanos lá, "nós" aqui.

Além disso, a imagem dos revolucionários como arquitetos da destruição lembra a constante crítica de Cairu aos maçons (seu desafeto principal é G onçalves $L^{(e d o)^{7}}$. C rítica tão mais significativa quanto Silva Lisboa os veja como "arquitetos de ruínas", el e que exatamente inicia a sua C onsti tuição M oral edeve res do cidadão com uma passagem de Gibbon, no Declínio e queda do I mpério R omano, em que boa planta da civilização cristã cresce no solo das ruínas do I mpério Romano. A analogia é possível, e parece plausível: Roma, a cidade pecaminosa, deixa-se suplantar pela nova civilização cristã. Paris, palco da barbárie revolucionária, oferece o quadro da perdição contra o qual (e a partir de cuja destruição) vai se erguer uma nova civilização, desta vez nos trópicos, mas retomando as pedras e as boas construções da Antigüidade. U ma arquitetura contra o tempo revolucionário, portanto.

Cairu desenvolve continuamente seus argumentos com imagens pal páveis, fortes, amiúde de origem orgânica. Sobretudo, a resolução como desvio da or- 
dem é para ele também uma questão física. $N$ ão será à toa se um dos vilões desse cuidadoso leitor de latim e grego será, justamente, Epicuro.

E picuro, o filósofo a partir do qual se ousa imaginar uma física dos infinitos mundos e, portanto, das infinitas possibilidades. U ma filosofia capaz de sugerir que a dimensão da liberdade se guarda no momento do desvio, na impossibilidade de determinação prévia do que será o mundo no seu próximo instante. A verdade é que 0 universo escolástico de Cairu, e com ele toda a sua arquitetura política (arquitetura da cidade), não resistira ao mundo dos desvios, dos "ligeiros desvios" sugeridos por E picuro e que chegaram até nós pela via latina de $D$ iógenes L aércio.

$\mathrm{H}$ á pelo menos um momento, uma bela passagem da Constituição moral e deveres do cidadão, em que a Revolução, como desvio da correta natureza do corpo social, parece associar-se indubitavelmente ao nome de E picuro:

$\mathrm{H}$ um dos maiores maleficios das R evoluções he o soltar dos laços da subordinação, e do dever do trabalho, regular e paciente, as classes industriosas, dando aos indivíduos ousadias insolentes para exorbitarem da própria esphera (M irabeau, hum dos mais atrabiliarios Coryphêos da C abala R evolucionaria da França, apregoou, que se devião castigar nos ricos os crimes dos pobres, como causas delles), e de, em lugar de cada obreiro ter a justa emulação de rivalisar em barateza e perfeição d'obra na sua arte entre os seus iguaes em méstér, e (por assim dizer) conseguir excellencia a alteza da mestrança e principado na respectiva classe, pela preeminência de sua habilidade e destreza; se arrojão temerários ao vacuo cahotico de ambição desordenada de soberania política, mais desenvoltos e desorientados que os átomos de Epicureo na immensidade do espaço, ou das muleculas d'agoa do salitre reduzidas á vapor pela explosão da polvora'.

H á no horizonte da revolução uma polvorada epicuriana, imagem assaz eloqüente, capaz de significar que a razão se perdeu no desvio e que a ordem faleceu diante do caos. Repare-se nessa passagem que os indivíduos - que num raciocínio liberal clássico deveriam ocupar-se com suas justas habilidades (ou "mesteres", nessa significativa intrusão léxica do arcaico no tecido discursivo de um liberal ismo que se pretende moderno), os indivíduos repentinamente se perdem no mundo da cidade, no universo da pólis, da política: "se arrojão temerários ao vácuo cahotico de ambição desordenada de soberania política, mais desenvoltos e desorientados que os atomos de Epicureo na immensidade do espaço, ou das muleculas d'agoa do satitre reduzidas á vapor pela explosão da pólvora". O que orienta essa explosão terrível - a própria R evolução figurada - é a ambição e a desorientação dos átomos.

O ra, lembremos que Cícero traduziria os átomos de Epicuro pelo latim individua ${ }^{8}$. A tradução é precisa: átomo é o indivíduo, o que não se divide. $M$ as a carga de sentido político dessa palavra - indivíduo num texto escrito para a fundação de um I mpério, em pleno século XIX, na contramão da Revolução da França e do $\mathrm{H}$ aiti, é inequívoca. $\mathrm{O}$ drama parece disparar-se nesse terrível momento em que o indivíduo, ou átomo, ousou desviar sua trajetória original, e nós 
sabemos que o desvio, do ponto de vista epicuriano, se dá sobre o vazio, sobre o vácuo, 0 inane.

$\mathrm{N}$ ada mais contrário à civilização (que é a própria construção) do que 0 inane, ou o vazio que ameaça toda a edificação, como é aliás o vazio do abismo diante do qual se experimenta a vertigem do definitivo desvio - a morte.

Estudando em detal he o texto de C airu e sua riquíssima rede intertextual, poderá o pesquisador perguntar o que haveria de tão fascinante e terrível nesse abismo da dissolução, capaz de obsedar um homem que justamente profere 0 discurso da O rdem. O rdem que, no plano das metáforas orgânicas em que ele opera, é o estado de normalidade a que se retorna, depois de um choque, e que reverte, ou evita, a corrupção do tecido, o apodrecimento do corpo.

Seguindo a trilha aberta por Cairu, a idéia de um choque febril sugere que a civilização se fortalece com o desvio - idéia inaugural da Sociologia clássica francesa - que ela até mesmo requer e se alimenta do temor do desvio.

Como última passagem, destaco um trecho dos sermões do moralista escocês H ugh Blair, do século XVIII, que Cairu traduz e cita em sua C onstituição moral:

A M ão D ivina he visivel nos grandes effeitos que apparecem na Sociedade civil, quando commoções, e guerras abalão a Terra; quando Facções se enfurecem, e intestinas divisões embrulhão os reinos, que antes erão florente [sic]; á primeira vista parece, que a Providencia tem abandonado os negócios das $\mathrm{N}$ ações ás desordens das paixões humanas. Comtudo, do meio desta confusão, muitas vezes resurge a O rdem, e dos males passageiros se derivão vantagens permanentes. Por taes convulsões, as $\mathrm{N}$ ações se excitão e levantão da perigosa lethargia, em que a superabundância da riqueza, a longa paz, e a progressiva effeminação dos costumes, a havião abysmado. Então ellas parecem reviver para bem discernirem os seus interesses, e aprendem a tomar as convenientes medidas para segurança e defeza contra os seus inimigos.

Em consequencia desse excitamento, corrigem-se os prejuízos inveterados; descobrem-se as occultas fontes de perigo; desperta-se o Espírito Publico; e formase mais extenso e exacto conceito da F elicidade $\mathrm{N}$ acional. As corrupções em que to do o G overno he sujeito a cahir muitas vezes, só se rectifição pela fermentação no Corpo Politico; bem como os humores nocivos do corpo humano são expellidos pelo choque da febre. As tentativas contra a sabia, e bem estabelecida, Constituição civil tendem, em fim de conta, a fortificalla; e as desordens da licenciosidade, e facção ensinão os homens a melhor apreciarem os bens da tranqüilidade, e legal protecção ${ }^{9}$.

Finalizando, talvez um corte deliberadamente anacrônico permita esclarecer um pouco a origem da potência e mesmo da poética do discurso da O rdem, que é o Cairu.

O bserve-se, a propósito, a belíssima foto veiculada pelo site do $\mathrm{N}$ ew York Times na Internet, alguns dias após o 11 de setembro (Figura 2). 


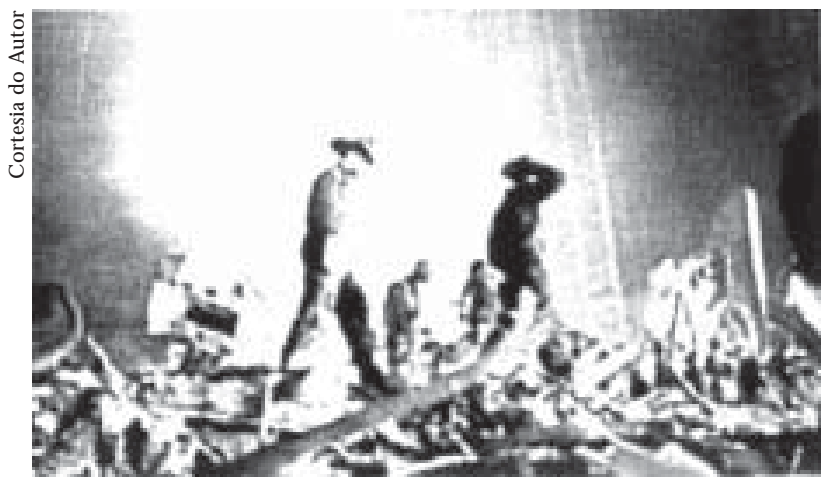

Figura 2 - "Firefighters on the ruble two days after the collapse of the twin towers. G radually, a rhythn descended upon the rescue efforts and order emerged from chaos." NY Times, September 30, 2001.

São desconcertantes as coincidências. A legenda do jornal norte-americano traz: "gradualmente, um ritmo desceu sobre os esforços de resgate e a ordem emergiu do caos".

D estaque-se uma descida que, ali, quase se configura numa benção: “a rhythm descended upon [...]" Lembrado o caráter providencial (divino, ou natural?) do choque para a boa manutenção do corpo, a proximidade com o discurso moralista setecentista nos põe a pensar.

O s bombeiros são aqui agentes da O rdem que verdadeiramente afloram das ruínas de uma civilização. Poderíamos mesmo dizer que, na construção poética - terrível - dessa imagem, os homens que buscam reinstaurar a ordem não apenas trabalham contra as ruínas, mas brotam delas. 0 tom fantasmagórico é instaurado pelas brumas iluminadas, e o combate ali, nós tristemente sabemos, é feito contra o vazio, contra nada.

$\mathrm{N}$ ão convém, porventura, arriscar uma análise de longa duração, mas fique aqui a sugestão da possível riqueza poética de muito discurso conservador, sempre que se vale de metáforas orgânicas e médicas para reafirmar a inteireza do corpo - político - contra a ameaça da desintegração, que é um fantasma necessário a espreitar toda a construção de um discurso civilizado. Enfim, a sugestão é que leiamos Cairu e os conservadores com mais cuidado. Talvez nós tenhamos bem mais a ver com eles do que queremos ou podemos admitir.

\section{N otas}

$1 \mathrm{Cf}$. Charles le Brun. Expressions des passions de l'A me. Numérisation BnF de l'édition de Paris, Aux amateurs de livre, 1990. (Gallica.) No original: "il dit que ce qui cause à I'Ame quelque pasion, fait faire au corps certains mouvemens, \& produit des alterations dont il rapporte lês principales". 
2 J osé da Silva Lisboa. C onstitui ção moral, e deveres do cidadão, com exposição da moral publica conforme o espírito da Constituição do império. R io de Janeiro, Typographia N acional, 1824-1825, 5 vols., parte II , p. 93. E dição comteporânea [ dos três primeiros volumes]: C onstitui ção moral, e deveres do cidadão... (Ed. Anoar Aiex). João Pessoa, Editora U niversitária/ U FPB, 1998.

$3 \mathrm{Cf}$. Fernando Antonio N ovaise J osé J obson de Andrade Arruda. "Prometeus e atlantes na forja da nação". Em J osé da Silva Lisboa. O bser vações sobre a franqueza da indús tria, e estabelecimento de fábricas no Brasil. Brasília, Senado Federal, 1999.

4 J osé da Silva Lisboa. op. cit., 1998, “Appendice”, pp. 85-101.

5 I dem, parte III, pp. 98-99.

6 Sobre a relação de Cairu com os maçons, e sua inserção no conturbado quadro das discurssões políticas dos anos de 1820, consulte-se I sabel L ustosa. Cairu, panfletário: contra a facção gálica e em defesa do trono e do altar. R io de J aneiro, Fundação Casa de Rui Barbosa, 1999 (Papéis avulsos, n. 34). Também I nsultosimpressos a guerra dos jornalistasna I ndependência (1821-1823). São Paulo, Companhia das L etras, 2000, passim.

7 J osé da Silva Lisboa. op. cit., 1998, "Supplemento", pp. 19-20.

8 Cf. J osé Kany-Turpin, "N otes". Em L ucrèce. D ela nature (D e rerum natura) (trad. José Kany-Turpin). Paris, Flammarion, 1998, p. 470.

9 José da Silva Lisboa, op. cit., 1998, parte II, pp. 139-140. N o original: "The divine hand is [...] apparent in the [... ] effects which it is appointed to produce to nations and societies. When wars and commotions shake the earth whwn factions rage, and intestine divisions embroil kingdoms that before were flourishing, Providence seems, at first view, to have abandoned public affairs to the misrule of human passions. Yet from the midst of this confulsion, order is often made to spring; and from these mischiefs lasting advantages to arise. By such convulsions, nations are roused from that dangerous lethargy into which flowing wealth, long peace, and growing effeminacy of manners had sunk them. They are awakened to discern their true interests; and taught to take proper measures for security and defense against all their foes. I nveterate prejudices are corrected; and latent sources of danger are discovered. Public spririt is called forth; and larger views of national happiness are formed. The corruptions to which every government is liable, are often rectified by a ferment in the political body, as noxious humours made against a wise and well-established civil constitution tend in the in the issue to strengthen it; and the disorders of licentiousness and faction, teach men more highly to prize the blessings of tranquility and legal protections. $\mathrm{H}$ ugh Blair. "Sermon V: O n the Divine Government of the Passions of M en", in Sermons. N ew York, Samuel Campbell, 1802, vol. II, pp. 84-85.

RESUMO - ESTE ARTIGO pretende resgatar, em traços largos, o caráter corretivo do discurso moralizador de J osé da Silva L isboa, o visconde de Cairu, em sua C onstitui ção moral e deveres do cidadão (1824-1825), sugerido, por meio de passagens brilhantes daquele tratado, como a imagem da R evolução, espelhando-se na experiência duplamente "catastrófica" da França e do H aiti, projeta-se sobre o cenário do N ovo I mpério que nascia. 
No registro conservador de Silva Lisboa, o discurso moralizador parece capaz de fundar uma nova Ordem nos trópicos, protegendo a "M ocidade Brasileira" da sedução dos princípios renovadores, mantendo firmes e bem atados os nós de um tecido social que a loucura dos revolucionários ameaçava, ao fazer despontar, no horizonte da jovem $\mathrm{N}$ ação, o perigo da dissolução e da corrupção do corpo político.

ABSTRACT - THIS ARTICLE intends to recover, in broad strokes, the corrective nature of the moralizing discourse of J osé da Silva L isboa, the visconde of Cairu, in his Constituição M oral e D everes do Cidadão (M oral Constitution and D uties of the C itizen) (18241825), and to suggest, through the use of that treatise's brilliant passagens, how the image of Revolution, modeled on the doubly "catastrophic" experiences of France and $\mathrm{H}$ aiti, projects itself onto the scenario of the nascent $\mathrm{N}$ ew Empire. In Silva Lisboa's conservative register, the moralizing discourse seems capable of founding a new $O$ rder in the tropic, og protecting "Brazilian Youth" from the seduction of renovating principles, of maintaining firm and well-tied the knots of a social fabric threatened by the madness of revolutionaries, who brought to the horizon of a young nation the danger of dissolotion and corruption of the body politic.

Pedro M eira M ontei ro é professor-assistente no departamento de Línguas e Culturas de Espanhol e Português, na U niversidade de Princeton, nos Estados U nidos. É autor de A queda do aventureiro (C ampinas, Editora da U nicamp, 1999).

Este trabalho é fruto de uma pesquisa de quatro anos, financiada pela Fundação de Amparo à Pesquisa do Estado de São Paulo (Fapesp), da qual resultaram este e outros artigos, além de um livro, U m moralista nos trópicos o visconde de C airu e o duque de la R ochefoucauld (São Paulo, Boitempo E ditorial, no prelo). 0 autor agradece particularmente a L uiz D antas, pelo diálogo sempre fecundo, e a Luiza Franco M oreira, cujo convite para participar de um simpósio por ela organizado, intitulado "N ação e Paixões", deu origem a este texto.

Texto recebido e aceito para publicação em 5 de agosto de 2003. 